\title{
Silica-based waste form for immobilization of iodine from reprocessing plant off-gas streams
}

Josef Matyáš $^{a,{ }^{*}}$, Nathan Canfield ${ }^{b}$, Sannoh Sulaiman ${ }^{a}$, and Mac Zumhoff ${ }^{a}$

${ }^{a}$ Radiological Materials \& Technology Development, Pacific Northwest National Laboratory, P.O. Box 999, Richland, WA 99352, United States

${ }^{b}$ Electrochemical Materials and Systems, Pacific Northwest National Laboratory, P.O. Box 999, Richland, WA 99352, United States

\begin{abstract}
A high selectivity and sorption capacity for iodine and a feasible consolidation to a durable $\mathrm{SiO}_{2}$-based waste form makes silver-functionalized silica aerogel $\left(\mathrm{Ag}^{0}\right.$-aerogel) an attractive choice for the removal and sequestration of iodine compounds from the off-gas of a nuclear fuel reprocessing plant. Hot uniaxial pressing of iodine-loaded $\mathrm{Ag}^{0}$-aerogel (20.2 mass\% iodine) at $1200^{\circ} \mathrm{C}$ for 30 min under $29 \mathrm{MPa}$ pressure provided a partially sintered product with residual open porosity of $16.9 \%$ that retained $~ 93 \%$ of sorbed iodine. Highly iodine-loaded $\mathrm{Ag}^{0}$-aerogel was successfully consolidated by hot isostatic pressing at $1200^{\circ} \mathrm{C}$ with a 30 -min hold and under $207 \mathrm{MPa}$. The fully densified waste form had a bulk density of 3.3 $\times 10^{3} \mathrm{~kg} / \mathrm{m}^{3}$ and contained $\sim 39$ mass $\%$ iodine. The iodine was retained in the form of nano- and microparticles of AgI that were uniformly distributed inside and along boundaries of fused silica grains.
\end{abstract}

Keywords: Immobilization; Iodine; Silver-functionalized silica aerogel; Hot uniaxial pressing; Hot isostatic pressing; Silica-based waste form

\section{Introduction}

The aqueous reprocessing of used nuclear fuel results in the release of various radionuclides into the offgas system with radioiodine $\left({ }^{129} \mathrm{I}\right)$ being of a particular concern because of its long half-life $\left(1.6 \times 10^{7}\right.$ years) and high mobility in the environment. Under current U.S. regulations [1-3], ${ }^{129}$ I must be captured and immobilized into a durable waste form for long-term storage in a geological disposal facility. These stringent regulations require an overall plant decontamination factor around 2000, which means that only one iodine atom out of 2000 is not captured by the sorbent [4,5]. It is, therefore, essential to develop

\footnotetext{
${ }^{*}$ Corresponding author. Tel: 1-509-372-6023; Fax: 1-509-372-5997

Email address: Josef.Matyas@pnnl.gov
} 
highly efficient sorbents for capture of iodine and waste forms for its safe disposal on a scale of geological time. A number of waste forms have been considered and are being developed worldwide for iodine conditioning such as low-melting glasses [6,7], sodalites [8,9], and apatite-like minerals [10-13]. However, none of these potential waste forms can be used as both a sorbent and a viable waste form. They can either encapsulate iodine loaded sorbent or sequester iodine that was removed from it. In the United States, the current benchmark material for radioiodine capture is reduced silver mordenite $\left(\mathrm{Ag}^{0} \mathrm{Z}\right)$ and that for the waste form is $\mathrm{Ag}^{0} \mathrm{Z}$ immobilized in a low-temperature glass composite material [14]. However, the primary alternative option for the removal and sequestration of iodine compounds from the off-gas of a nuclear fuel reprocessing plant is silver-functionalized silica aerogel ( $\mathrm{Ag}^{0}$-aerogel). This advanced material, which is synthesized in the form of granules bigger than $0.85 \mathrm{~mm}$ with a surface area $\sim 150 \mathrm{~m}^{2} / \mathrm{g}$, pore volume $\sim 0.5 \mathrm{~mL} / \mathrm{g}$, and bulk density $\sim 500 \mathrm{~kg} / \mathrm{m}^{3}$, exhibits excellent sorption properties for iodine. Iodine capacities up to $480 \mathrm{mg} / \mathrm{g}$ were demonstrated with decontamination factors over 10,000 in laboratory tests with simulated dissolver off-gas streams $[15,16]$. In addition, in contrast to $\mathrm{Ag}^{0} \mathrm{Z}, \mathrm{Ag}^{0}$ aerogel retained high selectivity and sorption capacity for iodine even after a long-term exposure to dry/humid air [17,18], dry air containing $2 \% \mathrm{NO}_{2}$ [19] and dry air containing $1 \% \mathrm{NO}$ [20]. This is important considering the possibility of the reprocessing plant idling, which would result in exposure of sorbent to heated air containing water vapor and possibly $\mathrm{NO}$ and $\mathrm{NO}_{2}$ gases.

A potentially simple conversion to a highly durable and leach-resistant $\mathrm{SiO}_{2}$-based waste form by simultaneous application of fast heating rates to temperatures above $1000^{\circ} \mathrm{C}$ and pressures up to $210 \mathrm{MPa}$ makes $\mathrm{Ag}^{0}$-aerogel an attractive choice for long-term immobilization of radioiodine. Previously, iodine retention of $>92 \%$ has been demonstrated in a hot uniaxially pressed sample [21]. Also, the preliminary investigation of the feasibility of hot isostatic pressing (HIP) for consolidating powders of $\mathrm{Ag}^{0}$-aerogel clearly showed that this method can be effectively used to produce material of near-theoretical density [22]. Promising preliminary results were also obtained for samples consolidated with spark plasma sintering (SPS), which offers the advantage of high densification rates at a lower processing temperature. 
The ram travel data for SPS indicated that rapid consolidation of powders can be performed at temperatures below $950^{\circ} \mathrm{C}$ due to enhanced sintering kinetics [22]. However, the high heating seems to occur preferentially at the grain boundaries and this local melting resulted in the particles and inclusions of Ag to be predominantly distributed at points of grain contacts. A small concentration of additives such as colloidal silica was needed to prevent accumulation of a large fraction of silver nanoparticles at the grain boundaries. Since HIP is a more mature technology than SPS and is now the baseline process for the high-level calcine waste at the Idaho National Laboratory Site [23] and for the intermediate-level waste byproducts of molybdenum-99 production in Australia [24], HIP processing was selected for further investigation.

The main purpose of the study reported here was to investigate HIP consolidation of $\mathrm{Ag}^{0}$-aerogel containing low and high concentration of non-radioactive iodine and determine whether a fully dense waste form can be produced and $100 \%$ retention of iodine achieved without using any additives. The study also investigated the effect of more material to prepare samples (1.5 vs. $0.5 \mathrm{~g}$ ) and the effect of prepressed pellets which were isostatically pressed at $345 \mathrm{MPa}$ before processing to achieve more intimate contact between particles, on consolidation with HIP. The consolidated samples were analyzed with a helium gas pycnometer for apparent density; with the Archimedes method for open porosity and apparent density; with scanning electron microscopy and energy dispersive spectroscopy (SEM-EDS) for the extent of densification, macro- and microstructural changes, and distribution of individual elements; and with X-ray diffraction (XRD) for crystalline phases.

\section{Experimental procedure}

\subsection{Materials}

Powders of $\mathrm{Ag}^{0}$-aerogel with or without iodine were prepared for processing with hot uniaxial pressing (HUP) and HIP. A batch of $\mathrm{Ag}^{0}$-aerogel granules with a particle size of less than $0.85 \mathrm{~mm}$ was synthesized using a previously developed procedure [15]. Briefly, the silver nanoparticles were produced on the propylthiol-modified pore surfaces of silica aerogel by reducing the silver thiolate adduct ions at 
$165^{\circ} \mathrm{C}$ for $2 \mathrm{~h}$ under flowing $2.7 \% \mathrm{H}_{2}$ in Ar. The granules were black in color with yellow spots and had a bulk density of $\sim 0.6 \times 10^{3} \mathrm{~kg} / \mathrm{m}^{3}$. Iodine-loaded $\mathrm{Ag}^{0}$-aerogel granules were prepared in a Teflon assembly shown in Figure 1. The bottom vessel contained $\sim 0.5$ or $3 \mathrm{~g}$ of solid non-radioactive iodine (the amount required to produce a low- or high- iodine-loaded material, respectively) and the top vessel contained four vials; each vial contained either $\sim 0.4$ or $1.2 \mathrm{~g}$ of $\mathrm{Ag}^{0}$-aerogel, depending on the amount of the material required for consolidation experiments. The assembly was kept in an oven at $150^{\circ} \mathrm{C}$ for $24 \mathrm{~h}$. Subsequently, the vials were removed from the assembly and left in the oven at $150^{\circ} \mathrm{C}$ for $1 \mathrm{~h}$ before being transferred into a desiccator for $1 \mathrm{~h}$ (kept under $10 \mathrm{kPa}$ in-house vacuum) to remove any physically adsorbed or condensed iodine. The mass gains, i.e., iodine loadings for the low-iodine-loaded samples ranged from 19.7 to 21.9 mass\% and for the high-iodine-loaded samples from 34.8 to 35.5 mass\% as determined with an analytical balance of $0.1 \mathrm{mg}$ sensitivity. The prepared samples were hand ground with a mortar and pestle before consolidation with HUP and HIP.

\subsection{Methods of densification}

Two methods, HUP and HIP, were investigated to effectively consolidate $\mathrm{Ag}^{0}$-aerogel containing or lacking iodine into a fully dense silica-based waste form.

\subsubsection{Hot uniaxial pressing}

Two powdery samples of $\mathrm{Ag}^{0}$-aerogel were consolidated with HUP, one with and one without iodine but both containing 8 mass\% organic moiety (installed on the surface of the pores during the synthesis of $\mathrm{Ag}^{0}$-aerogel). The iodine-loaded sample contained 20.2 mass\% iodine (removal of organic moiety increases concentration of iodine to 22.0 mass\%). Approximately 0.2-g samples were loaded into alumina crucibles $(9.55 \mathrm{~mm}$ OD × $6.42 \mathrm{~mm}$ ID × $19.10 \mathrm{~mm}$ tall $)$, covered with an alumina lid, and compressed with a $6 \mathrm{~kg}$ weight on the plunger rod. Each of these crucibles, one at a time, was secured with a Pt wire spring to the alumina push rod, which was mounted to the Duramaster rod cylinder (Greenco Mfg. Corporation, Tampa, FL) outside of the furnace. The rod cylinder was pressurized with air, extending the push rod and compressing the sample in the crucible with 29 MPa pressure against a 
mullite block inside the furnace that was preheated to $1200^{\circ} \mathrm{C}$. After $30 \mathrm{~min}$, the rod was retracted from the furnace and the crucible was removed and transferred into a desiccator for an hour before being weighed on a four-digit balance to determine mass loss (used to calculate iodine retention in the product).

\subsubsection{Hot isostatic pressing}

Table 1 shows two sets of two samples of $\mathrm{Ag}^{0}$-aerogel that were consolidated with HIP, each set containing samples with and without iodine. The organic moiety was removed from all samples without iodine loss (the samples were heated from 25 to $350^{\circ} \mathrm{C}$ at a rate of $5^{\circ} \mathrm{C} / \mathrm{min}$, held at $350^{\circ} \mathrm{C}$ for $10 \mathrm{~min}$, and air quenched) because gases evolved from its decomposition can prevent densification of the powder inside the metal fixture [22]. The first set of samples was prepared from powders of $\mathrm{Ag}^{0}$-aerogel that already had the organic moiety removed. Approximately 0.4-0.5 g was pressed into 14.9 mm pellets ( 1 mm thick) with a benchtop Carver press (Carver, Inc., Wabash, IN) at 62 MPa before being transferred into an 15 mm dimple ( $1 \mathrm{~mm}$ deep) in the circular $0.016 \mathrm{~mm}$ thick tantalum sheet (38 $\mathrm{mm}$ in diameter) and covered by a circular flat sheet, also $38 \mathrm{~mm}$ in diameter. The second set of samples was prepared using a three-step process: 1) 1-1.5 g of powdery samples were prepressed under 9 MPa pressure with a benchtop Carver press, 2) the prepressed pellets were isostatically pressed under 345 MPa with a research-scale isostatic press (CIP32260, Avure Technologies, Columbus, OH), and 3) isostatically pressed pellets were heat treated to remove the organic moiety. Each pellet was then transferred into a tantalum fixture made of two circular 0.016-mm-thick tantalum sheets (38 $\mathrm{mm}$ in diameter), each with a 15-mm-diameter dimple ( 1.5 mm deep). These two sheets were placed opposite each other so that the pair of dimples formed a volume to hold the pellets. The inside surfaces of the circular sheets were coated with carbon for easier removal of the samples. The fixtures with samples were then degassed at approximately $0.01 \mathrm{~Pa}$, sealed by electron-beam welding, and processed with HIP at American Isostatic Pressing (Columbus, $\mathrm{OH}$ ) in a research-scale HIP instrument, which had carbon heating elements and used argon gas to pressurize the chamber. All four fixtures were processed at the same time and were heated at $20^{\circ} \mathrm{C} / \mathrm{min}$ from room temperature to $1200^{\circ} \mathrm{C}$ with a 30 -min hold and consolidated under 
$207 \mathrm{MPa}$. Figure 2 shows the temperature and pressure profiles for the samples during processing with HIP.

\subsection{Sample characterization}

The consolidated samples were analyzed with a helium gas pycnometer for apparent density; with the Archimedes method for open porosity and apparent density; with SEM-EDS for the extent of densification, macro- and microstructural changes, and distribution of individual elements; and with XRD for crystalline phases.

\subsubsection{Density - Archimedes method}

The samples were weighed on an analytical balance (Sartorius model A200S, Brinkmann Instruments Co., Westbury, New York) to an accuracy of $0.1 \mathrm{mg}\left(m_{d r y}\right)$ before being suspended in ethanol (EtOH) for $2 \mathrm{~h}$ under in-house vacuum $(10 \mathrm{kPa})$ to allow the EtOH to penetrate any open and surface-connected porosity. The samples were then weighed both suspended in EtOH $\left(m_{\text {sus }}\right)$ and in air saturated with EtOH $\left(m_{\text {sat }}\right)$. The apparent densities of the samples were calculated according to Eq. (1):

$$
\rho_{\text {sample }}=\frac{m_{d r y} \rho_{E t O H}}{\left(m_{\text {sat }}-m_{\text {sus }}\right)}
$$

where $m_{i}$ is the mass in the $i$-th configuration ( $i=$ dry, saturated and suspended, respectively), and $\rho_{E t O H}$ is the density of EtOH at the temperature of the test $\left(0.79029 \times 10^{3} \mathrm{~kg} / \mathrm{m}^{3}\right.$ at $\left.19^{\circ} \mathrm{C}\right)$ [25]. The open porosity of the samples was calculated according to Eq. (2):

$$
\% \text { OpenPorosity }=\frac{\left(m_{\text {sat }}-m_{\text {dry }}\right)}{\left(m_{\text {sat }}-m_{\text {sus }}\right)} \times 100
$$

A sample of aluminum with a density $2.7000 \times 10^{3} \mathrm{~kg} / \mathrm{m}^{3}$ and zero open porosity was run in duplicate with the samples to validate the obtained densities and open porosities. The measured densities, 2.6950 and $2.6899 \times 10^{3} \mathrm{~kg} / \mathrm{m}^{3}$, and open porosities, 0.07 and $0.43 \%$, were in good agreement with values for aluminum metal. 


\subsubsection{Density - helium pycnometry}

A helium pycnometer (AccuPyc II 1340, Micromeritics Inc., Norcross, GA) was used to validate apparent densities obtained with the Archimedes method. The apparent density was calculated using the known sample mass and an apparent volume (the volume of the solid material excluding surface-connected porosity, but including closed pores) that was determined by measuring the pressure change of helium (99.995\%) in a calibrated volume. The pycnometer was operated with a $1 \mathrm{~mL}$ sample cup. The volume of the cup was calibrated with a $0.7182 \pm 0.0001 \mathrm{~mL}$ tungsten cylinder. The calibration was checked with a sample of aluminum of known density, $2.7000 \times 10^{3} \mathrm{~kg} / \mathrm{m}^{3}$, at $20^{\circ} \mathrm{C}$. The measured density of $2.6860 \pm$ $0.0056 \times 10^{3} \mathrm{~kg} / \mathrm{m}^{3}$ was in good agreement with the density of the standard.

The samples were weighed on an analytical balance to the nearest $0.1 \mathrm{mg}$. The cup with samples was purged (cell filling/expulsion of helium) 10 times to remove air and moisture from the sample and the inside of the chamber. This was followed by 10 measurement cycles of the sample volume for density determination, the results of which were averaged.

\subsubsection{Scanning electron microscopy and energy dispersive spectroscopy}

A JEOL JSM-7001F/TTLS scanning electron microscope (JEOL USA, Inc., Peabody, MA) equipped with a field emission gun was used to examine polished thin sections of selected samples in low vacuum mode at an accelerating voltage of $15 \mathrm{kV}$ to minimize beam penetration. Polished cross sections were analyzed for the extent of densification, the amount of open porosity, and the character of grain boundaries. An EDAX Si-drift detector was used to conduct EDS (Apollo XL, AMETEK, Berwyn, PA) for elemental spot analysis and dot mapping, which revealed the distribution of individual elements in densified samples.

\subsubsection{X-ray diffraction}

The samples were hand-ground to a fine powder with an agate mortar and pestle. This powder was dispersed in a couple of drops of EtOH before being collected with a pipette and deposited on the surfaces of zero-background XRD sample holders. The samples were scanned with an X-ray diffractometer (Bruker D8 Advanced; Bruker AXS Inc., Madison, WI) configured with a $\mathrm{Cu} \mathrm{K \alpha} \operatorname{target}(\lambda=1.5406 \AA)$ 
set to a power level of $40 \mathrm{kV}$ and $40 \mathrm{~mA}$, goniometer radius of $250 \mathrm{~mm}, 0.3^{\circ}$ fixed divergence slit, and LynxEye ${ }^{\mathrm{TM}}$ position-sensitive detector with a collection window of $3^{\circ} 2 \theta$. The scan parameters were $0.03^{\circ} 2 \theta$ step size, $4 \mathrm{~s}$ dwell time, and 5 to $70^{\circ} 2 \theta$ scan range. Bruker AXS DIFFRACplus EVA software was used to identify crystalline phases.

\section{Results and discussion}

\subsection{Hot uniaxial pressing}

Figure 3 shows an SEM backscattered electron image of iodine-loaded $\mathrm{Ag}^{0}$-aerogel after processing with HUP. The different shades of gray for silica grains correspond to different concentrations of uniformly dispersed nanoparticles of $\mathrm{Ag}, \mathrm{Ag}_{2} \mathrm{~S}$, and $\mathrm{AgI}$. In addition, micrometer-sized nodules of $\mathrm{Ag}, \mathrm{Ag}_{2} \mathrm{~S}$, and AgI formed at grain boundaries. It was hypothesized that grinding of $\mathrm{Ag}^{0}$-aerogel granules with a mortar and pestle produced particles with fractured surfaces covered by Ag and AgI nanoparticles. Since the melting temperatures of $\mathrm{Ag}$ and $\mathrm{AgI}$ are $961^{\circ} \mathrm{C}$ and $558^{\circ}$, respectively, these nanoparticles would coalescence at the grain boundaries and form micrometer-sized nodules by capillary forces and viscous flow during sintering at $1200^{\circ} \mathrm{C}$. The $\mathrm{Ag}_{2} \mathrm{~S}$ was produced during the processing by a reaction of silver with thiols which were anchored onto the pores surfaces of silica aerogel during preparation of $\mathrm{Ag}^{0}$ aerogel. The sample was not fully sintered as evidenced by the presence of small cavities. This agreed well with the open porosity of $\sim 16.9 \%$ measured by the Archimedes method. The initial mass of iodineloaded $\mathrm{Ag}^{0}$-aerogel sample was $239.5 \mathrm{mg}$, of which $48.4 \mathrm{mg}$ (20.2 mass\% of total) was iodine and the remaining $191.1 \mathrm{mg}$ was $\mathrm{Ag}^{0}$-aerogel. If only $\mathrm{Ag}^{0}$-aerogel was processed with HUP, the sample lost 16.3 mass\%. This converts to a loss of $31.2 \mathrm{mg}$ for $191.1 \mathrm{mg}$ of $\mathrm{Ag}^{0}$-aerogel. However, the actual mass loss was $34.8 \mathrm{mg}$. The extra loss of $3.6 \mathrm{mg}$ is related to iodine and resulted in the retention of $92.6 \%$ of sorbed iodine in the sintered product. This value is similar to an iodine retention of $92.2 \%$ that was observed for a sample that initially contained 15.4 mass\% of iodine and that was heat-treated under the same conditions $\left(1200^{\circ} \mathrm{C}\right.$ for $\left.30 \mathrm{~min}\right)$ but at a lower pressure of $0.1 \mathrm{MPa}$ [10]. 


\subsection{Hot isostatic pressing}

Figure 4 shows a SEM backscattered electron image of $\mathrm{Ag}^{0}$-aerogel (HIP-1) after processing with HIP. The sample was fully densified and had an apparent density of $3.0918 \pm 0.0256 \times 10^{3} \mathrm{~kg} / \mathrm{m}^{3}$. Table 2 shows EDS analysis of four different areas for this sample. Concentrations of Ag varied from 3 mass\% in black areas to $\sim 37$ mass $\%$ in dark gray areas, $\sim 49$ mass $\%$ in light gray areas, and $\sim 80$ mass $\%$ in white micrometer-sized inclusions. An increased concentration of Ag was accompanied by increased concentration of sulfur, which varied from $<1$ mass $\%$ in black areas to $>10$ mass $\%$ in white spots. Similar to the samples processed with HUP, nanoparticles and micrometer-sized inclusions of Ag and $\mathrm{Ag}_{2} \mathrm{~S}$ were distributed throughout the grains and along grain boundaries of the consolidated product. Figure 5 shows the distribution of individual elements (Ag, I, and Si) and the morphology of particles in the HIP-processed iodine-loaded $\mathrm{Ag}^{0}$-aerogel (HIP-2). The fully densified sample had an apparent density of $3.2852 \pm 0.0245 \times 10^{3} \mathrm{~kg} / \mathrm{m}^{3}$ and contained $\sim 22$ mass $\%$ of iodine. Iodine was retained in the form of nano- and micro-particles of AgI, which were uniformly dispersed in the silica-based matrix. Some micrometer-sized inclusions of AgI were also located along grain boundaries. It remains to be determined whether the presence of AgI inclusions at the interface will result in faster release of iodine from the densified product. However, it is expected that the release of iodine will be limited by the physical barrier provided by the encapsulating silica matrix. The dissolution rates of AgI in the interior are expected to be much lower owing to the limiting effects of mass transport. The presence of other crystalline phases such as $\mathrm{Ag}$ and $\mathrm{Ag}_{2} \mathrm{~S}$ was confirmed by XRD analysis as shown in Figure 6. The lack of open porosity and $100 \%$ retention of iodine in the consolidated product indicated that for iodine loadings (concentrations of captured iodine) 20 mass\% there will be no need for additives to enhance the sintering process.

Figure 7 details the distribution and morphology of $\mathrm{AgI}$ and $\mathrm{Ag}_{2} \mathrm{~S}$ inclusions in the HIP-consolidated iodine-loaded $\mathrm{Ag}^{0}$-aerogel (HIP-4). The fully densified sample had an apparent density of $3.246 \times 10^{3}$ $\mathrm{kg} / \mathrm{m}^{3}$ as measured with the Archimedes method. The density was in good agreement with the $3.2618 \pm$ $0.0082 \times 10^{3} \mathrm{~kg} / \mathrm{m}^{3}$ obtained with a gas pycnometer measurement. The sample contained $\sim 39$ mass\% 
iodine which was retained in the form of nano- and micro-particles of AgI. These particles were uniformly dispersed in the silica-based matrix. The presence of crystalline phases such as $\mathrm{AgI}$ and $\mathrm{Ag}_{2} \mathrm{~S}$ was confirmed by XRD analysis, the results of which are shown in Figure 8. The lack of open porosity and $100 \%$ retention of iodine in the consolidated product indicated that, even for iodine loadings (concentrations of captured iodine) close to 40 mass\%, there will be no need to include additives to enhance the sintering process and produce a fully consolidated waste form. Figure 9 shows a high magnification image of sample HIP-4 that indicates areas used to determine elemental composition with EDS measurement. The EDS data, shown in Table 3, shows that the concentrations of Ag and I ranged from 5.5 to 26.4 mass\% and from 2.9 to 7 mass\%, respectively. The concentration of sulfur remained nearly constant, $\sim 0.3-0.4$ mass\%.

These results show excellent consolidation of the iodine-loaded $\mathrm{Ag}^{0}$-aerogel with HIP, considering the limited number of samples run to date. 


\section{Conclusion}

The results from consolidation tests clearly showed that rapid consolidation of iodine-loaded $\mathrm{Ag}^{0}$-aerogel with HUP and HIP yields a final waste form consisting of AgI particles encapsulated in a silica-based matrix. HUP-processing $\left(1200^{\circ} \mathrm{C}\right.$ for 30 min under $29 \mathrm{MPa}$ pressure) of $\mathrm{Ag}^{0}$-aerogel loaded with 20.2 mass\% of iodine did not produce a fully dense product but a sintered product with a residual open porosity of $16.9 \%$. Interestingly, $~ 93 \%$ of sorbed iodine was still retained in the sintered material. In contrast, densification of iodine-loaded $\mathrm{Ag}^{0}$-aerogel containing 20.2 mass\% iodine with $\mathrm{HIP}$ at $1200^{\circ} \mathrm{C}$ for 30 min under $207 \mathrm{MPa}$ pressure resulted in a fully dense silica-based waste form of $3.3 \times 10^{3} \mathrm{~kg} / \mathrm{m}^{3}$ bulk density containing 22 mass\% iodine. Iodine was retained in the form of nano- and microinclusions of AgI dispersed in the silica matrix. The lack of open porosity and $100 \%$ retention of iodine in the consolidated product indicated that additives were not needed to enhance the sintering process. This was confirmed even for higher iodine loadings close to 40 mass\%. Highly iodine-loaded $\mathrm{Ag}^{0}$ aerogel was successfully consolidated using HIP under the same conditions as the low-iodine-loaded sample. The fully densified product had a bulk density of $3.3 \times 10^{3} \mathrm{~kg} / \mathrm{m}^{3}$ and contained $\sim 39$ mass\% of iodine which was also retained in the form of nano- and micro-particles of AgI. However, the chemical durability testing of densified products will tell whether additives such as raw silica aerogel are required to enhance the long-term performance of the high-iodine-loaded waste form. It is expected that for a fully densified waste form with uniformly distributed inclusions of AgI the release of iodine will be limited by the physical barrier provided by the encapsulating silica matrix. In addition, scale-up of the consolidation with HIP is needed to demonstrate the effectiveness of this method. This should not be difficult considering that HIP is well established at commercial scales. However, HIP-processing requires material to be encapsulated in a container, such as Ta, which needs to be designed to generate a product of reliable shape and dimensions.

\section{Acknowledgements}

This work was funded by the U.S. Department of Energy’s Fuel Cycle Research and Development

Program. The Pacific Northwest National Laboratory is a multiprogram laboratory operated by Battelle under Contract Number DE-AC05-76RL01830.

\section{References}

[1] 40 CFR 190.10 Environmental Radiation Protection Standards for Nuclear Power Operations, Environmental Protection Agency, Washington, DC (2010).

[2] 40 CFR 191.13 Environmental Radiation Protection Standards for Management and Disposal of Spent Nuclear Fuel, High-level and Transuranic Radioactive Wastes, Environmental Protection Agency, Washington, DC (2010).

[3] 10 CFR 20 Standards for Protection against Radiation, Nuclear Regulatory Commission, Washington, DC (2012).

[4] R. Jubin, N. Soelberg, D. Strachan, G. Ilas, Fuel Age Impacts on Gaseous Fission Product Capture during Separations, FCRD-SWF-2012-000089, PNNL-22550 Oak Ridge National Laboratory, Oak Ridge, Tennessee 2012.

[5] N.R. Soelberg, T.G. Garn, M.R. Greenhalgh, J.D. Law, R. Jubin, D.M. Strachan, P.K. Thallapally, Sci. Technol. Nucl. Install., (2013) http://dx.doi.org/10.1155/2013/702496.

[6] T. Lemesle, F.O. Méar, L.Campayo, O. Pinet, B. Revel, L. Montagne, J. Haz. Mater. 264 (2014) 117126. 
[7] T.M. Nenoff, J.L. Krumhansl, T.J. Garino, N.W. Ockwig, Patent n ${ }^{0} U S 8,262,950 B 1$ (9/11/12).

[8] E.R. Madrell, P.K. Abraitis, Mater. Res. Soc. Symp. Proc. 807 (2004) 261-266.

[9] G.P. Sheppard, J.A. Hriljac, E.R. Maddrell, N.C. Hyatt, Mater. Res. Soc. Symp. Proc. 932 (2006) 775782.

[10] L. Campayo, S. Le Gallet, D. Perret, E. Courtois, C. Cau Dit Coumes, Yu. Grin, F. Bernard, J. Nucl. Mater. 457 (2015) 63-71.

[11] M.C. Stennett, I.J. Pinnock, N.C. Hyatt, 414 (3) (2011) 352-359.

[12] S. Le Gallet, L. Campayo, E. Courtois, S. Hoffmann, Yu. Grin, F. Bernard, F. Bart, J. Nucl. Mater. 400 (3) (2010) 251-256.

[13] T. Yao, F. Lu, H. Sun, J. Wang, R.C. Ewing, J. Lian, J. Am. Cerm.Soc. 97 (8) (2014) 2409-2412.

[14] T. M. Nenoff, T.J. Garino, J.L. Krumhansl, D. Rademacher, R.T. Jubin, D. Haefner, Waste Form Development and testing for $\mathrm{I}_{2}$, AFCI-WAST-PMO-MI-DV-2009-0000156, Sandia National Laboratory, Albuquerque, New Mexico, 2008.

[15] J. Matyáš, G.E. Fryxell, B.J. Busche, K. Wallace, L.S. Fifield, Ceramic Engineering and Science, 32 (9) (2011) 23-33.

[16] N. Soelberg, T. Watson, Iodine Sorbent Performance in FY 2012 Deep Bed Tests, FCRD-SWF2012-000278 (INL/EXT-12-27075), Idaho National Laboratory, Idaho Falls, Idaho, 2012.

[17] S.H Bruffey, K.K. Anderson, R.T. Jubin, J.F. Walker Jr., Aging and iodine loading of silverfunctionalized aerogels, FCRD-SWF-2012-000256, Oak Ridge National Laboratory, Oak Ridge, Tennessee, 2012.

[18] S.H. Bruffey, K.K. Anderson, R.T. Jubin, J.F. Walker Jr., Humid Aging and Iodine Loading of Silver Functionalized Aerogels, FCRD-SWF-2013-000258, Oak Ridge National Laboratory, Oak Ridge, Tennessee, 2013.

[19] R.T. Jubin, S.H. Bruffey, K.K. Patton, Humid Aging and Iodine Loading of Silver-Functionalized Aerogels, FCRG-SWF-2014-000594, Oak Ridge National Laboratory, Oak Ridge, Tennessee, 2014.

[20] S.H. Bruffey., K.K. Patton, R.T. Jubin, Complete Iodine Loading of NO-Aged $\mathrm{Ag}^{0}$-Functionalized Silica Aerogel, FCRD-MRWFD-2015-000419, Oak Ridge National Laboratory, Oak Ridge, Tennessee, 2015.

[21] J. Matyáš, M.J. Robinson, G.E. Fryxell, Ceramic Engineering and Science, 33 (9) (2012) 121-125.

[22] J. Matyáš, R.K. Engler, Assessment of methods to consolidate iodine-loaded silver-functionalized silica aerogel, FCRD-SWF-2013-000589, Pacific Northwest National Laboratory, Richland, Washington, 2013.

[23] Y. Zhang, H. Li, P.J. McGinn, B. Yang, B.D. Begg, J. Nucl. Mater. 375 (3) (2008) 15-22.

[24] ANSTO, Management of Radioactive Waste in Australia, Australian Nuclear Science and Technology Organization, Lucas Heights, NSW Australia, 2011.

[25] ASTM C693-93, Standard Test Method for Density of Glass by Buoyancy, ASTM International, West Conshohocken, PA (2013). 


\section{Tables and Figures}

Table 1. Samples of $\mathrm{Ag}^{0}$-aerogel processed with HIP. ${ }^{\text {(a) }}$ Organic moiety from functionalization was removed by ramp-heating at $5^{\circ} \mathrm{C} / \mathrm{min}$ from room temperature to $350^{\circ} \mathrm{C}$, holding at $350^{\circ} \mathrm{C}$ for $10 \mathrm{~min}$, and air quenching. ${ }^{(b)}$ Iodine loading after removal of organic moiety (HIP-2 and HIP-4 contained $\sim 8$ and 10 mass\% organic moiety, respectively).

\begin{tabular}{|c|c|c|}
\hline Sample ID & \multirow{2}{*}{$\begin{array}{c}\text { Organic } \\
\text { Moiety }\end{array}$} & $\begin{array}{c}\text { Iodine }^{(\mathrm{b})} \\
\text { (mass\%) }^{(\mathrm{a}}\end{array}$ \\
\hline \multirow{3}{*}{ HIP-1 } & & 0 \\
\hline HIP-2 & \multirow{2}{*}{ removed } & 22.1 \\
\cline { 1 - 1 } HIP-3 & & 0 \\
\hline HIP-4 & & 38.8 \\
\hline
\end{tabular}


Table 2. Concentrations of Ag, S, Si, and O in mass\% for areas from Figure 4 (HIP-1, area 1-4).

\begin{tabular}{|c|c|c|c|c|}
\hline Area & Si & O & Ag & S \\
\hline 1 & 29.39 & 28.70 & 37.43 & 4.48 \\
\hline 2 & 49.75 & 46.72 & 2.78 & 0.75 \\
\hline 3 & 22.36 & 22.34 & 49.29 & 6.01 \\
\hline 4 & 4.04 & 6.35 & 79.53 & 10.08 \\
\hline
\end{tabular}


Table 3. Concentrations of Si, O, Ag, and S in mass\% for areas from Figure 9 (HIP-4, areas 1-4).

\begin{tabular}{|c|c|c|c|c|c|}
\hline Area & Si & O & Ag & S & I \\
\hline 1 & 30.95 & 43.42 & 19.87 & 0.44 & 5.32 \\
\hline 2 & 34.81 & 55.94 & 5.55 & 0.23 & 3.47 \\
\hline 3 & 19.32 & 46.79 & 26.40 & 0.45 & 7.04 \\
\hline 4 & 29.51 & 56.35 & 10.86 & 0.34 & 2.94 \\
\hline
\end{tabular}




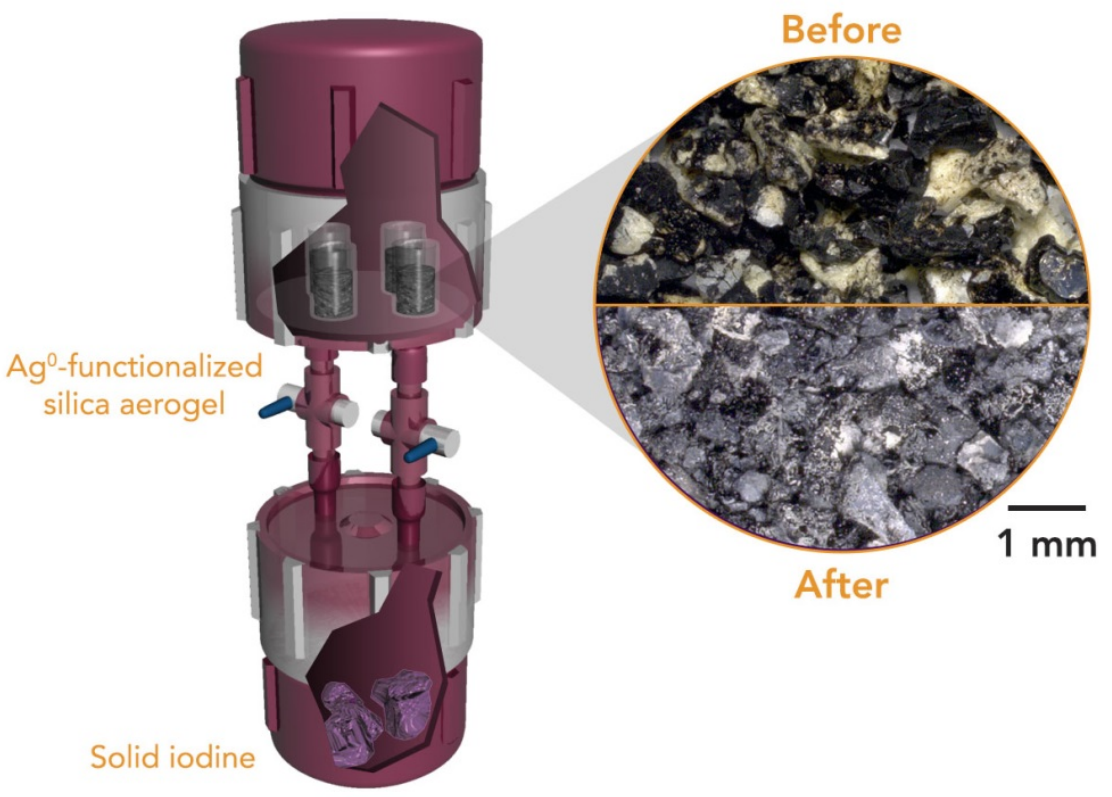

Figure 1. Assembly to produce iodine-loaded $\mathrm{Ag}^{0}$-aerogel; samples were exposed to iodine vapors at $150^{\circ} \mathrm{C}$ for $24 \mathrm{~h}$. 


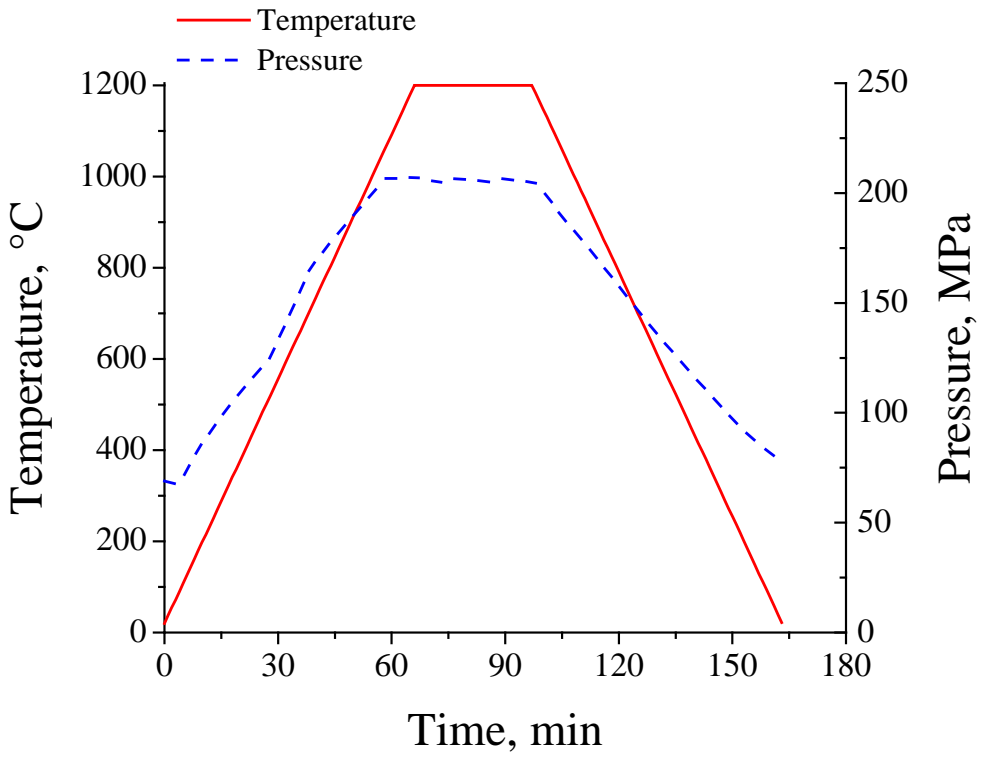

Figure 2. Temperature and pressure as a function of time for samples processed with HIP. 


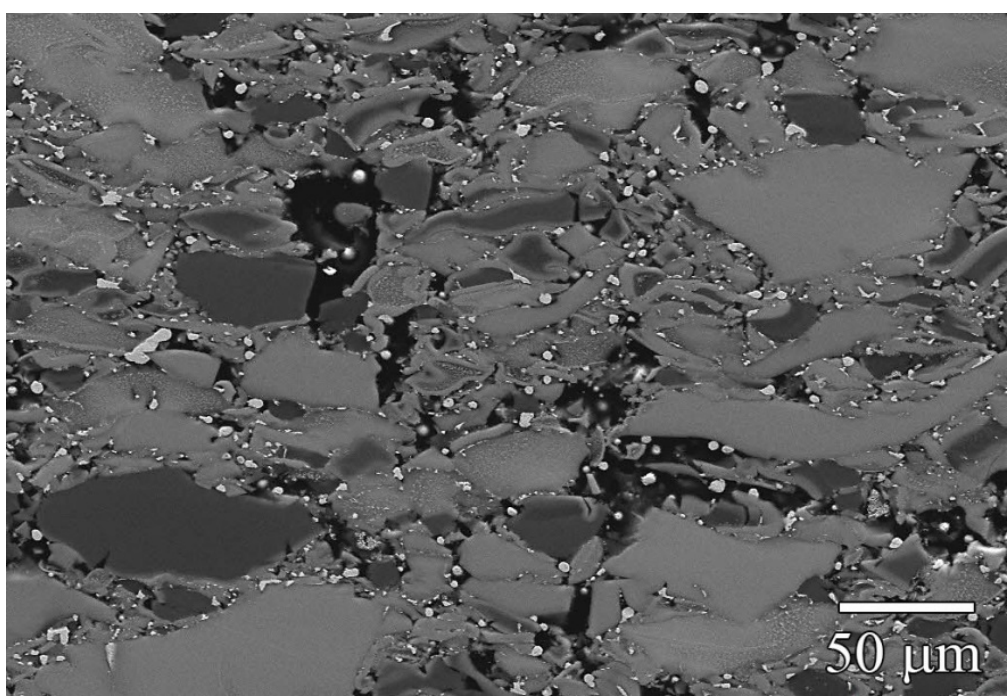

Figure 3. SEM backscattered electron image of HUP-processed iodine-loaded $\mathrm{Ag}^{0}$-aerogel. White and light gray spots are nanoparticles and micrometer-sized nodules of $\mathrm{Ag}, \mathrm{Ag}_{2} \mathrm{~S}$, and $\mathrm{AgI}$ distributed along or inside of silica grains. 


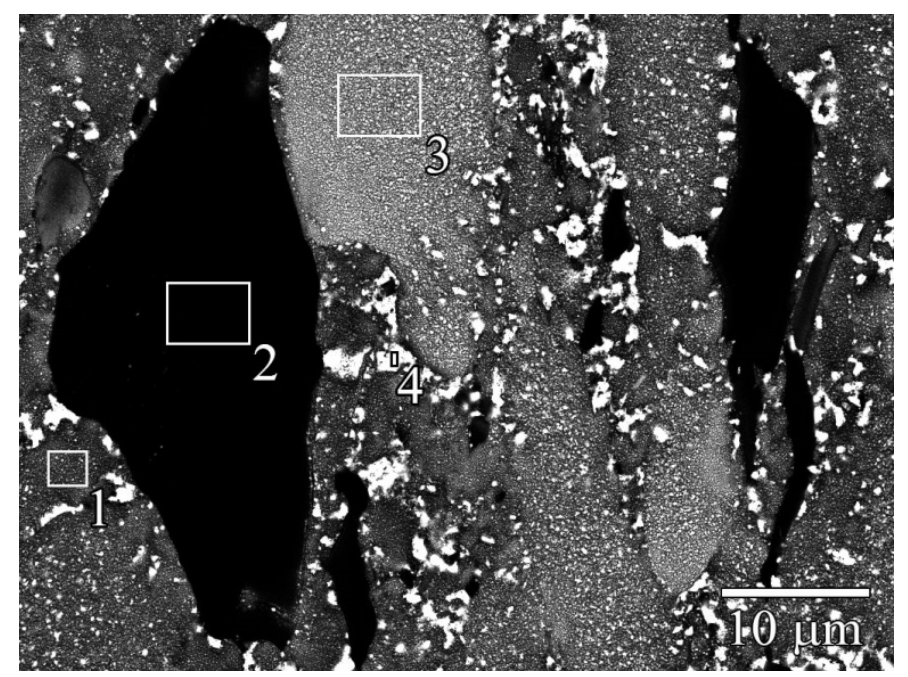

Figure 4. SEM backscattered electron image of HIP-processed $\mathrm{Ag}^{0}$-aerogel (HIP-1). White spots are nanoparticles and micrometer-sized nodules of $\mathrm{Ag}$ and $\mathrm{Ag}_{2} \mathrm{~S}$ distributed inside silica grains or along grain boundaries. 

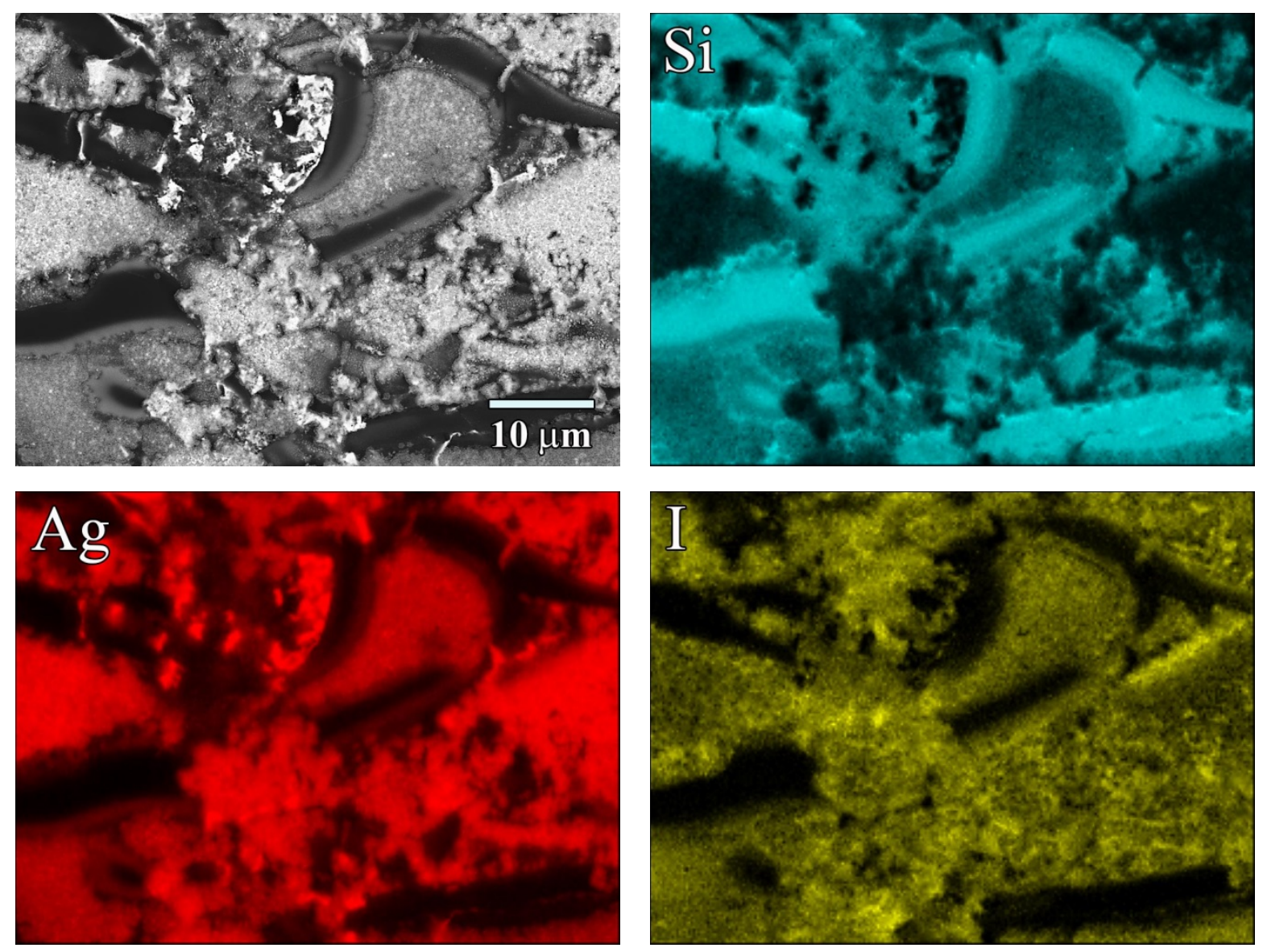

Figure 5. Elemental dot map of a small area of HIP-processed iodine-loaded $\mathrm{Ag}^{0}$-aerogel (HIP-2). Iodine loading 22.1 mass\%. 


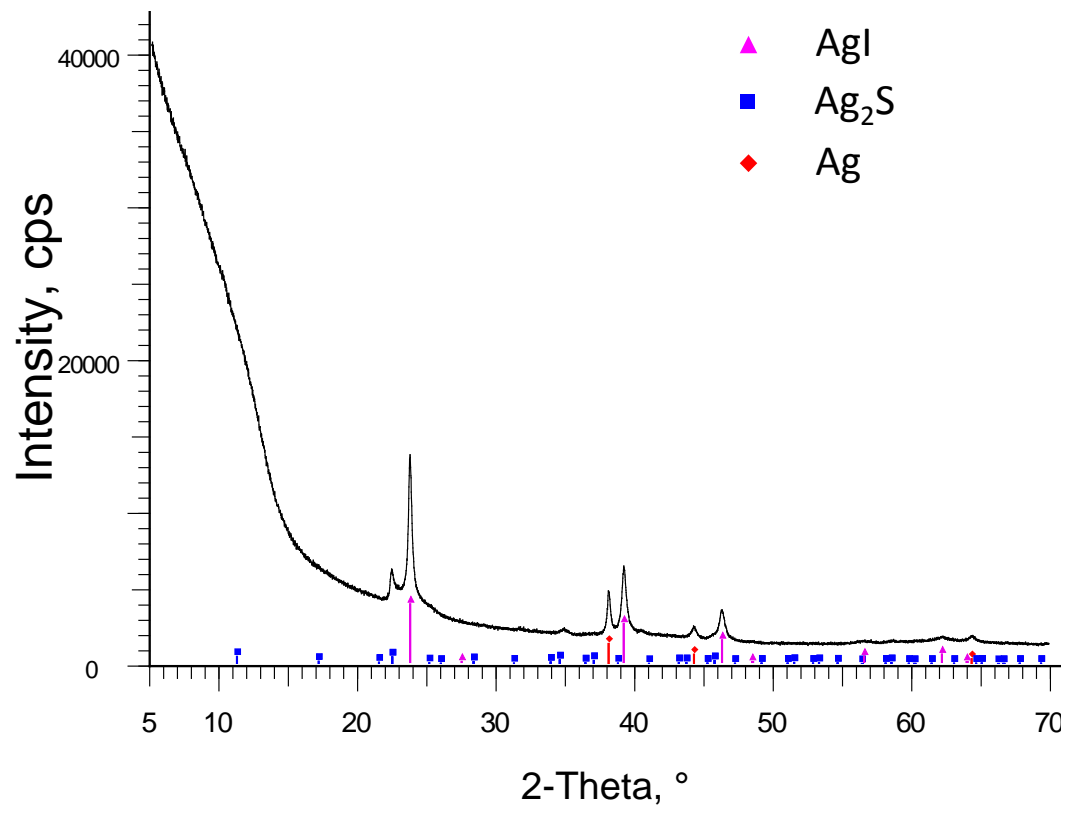

Figure 6. XRD pattern and identified phases for HIP-processed iodine-loaded $\mathrm{Ag}^{0}$-aerogel (HIP-2). 


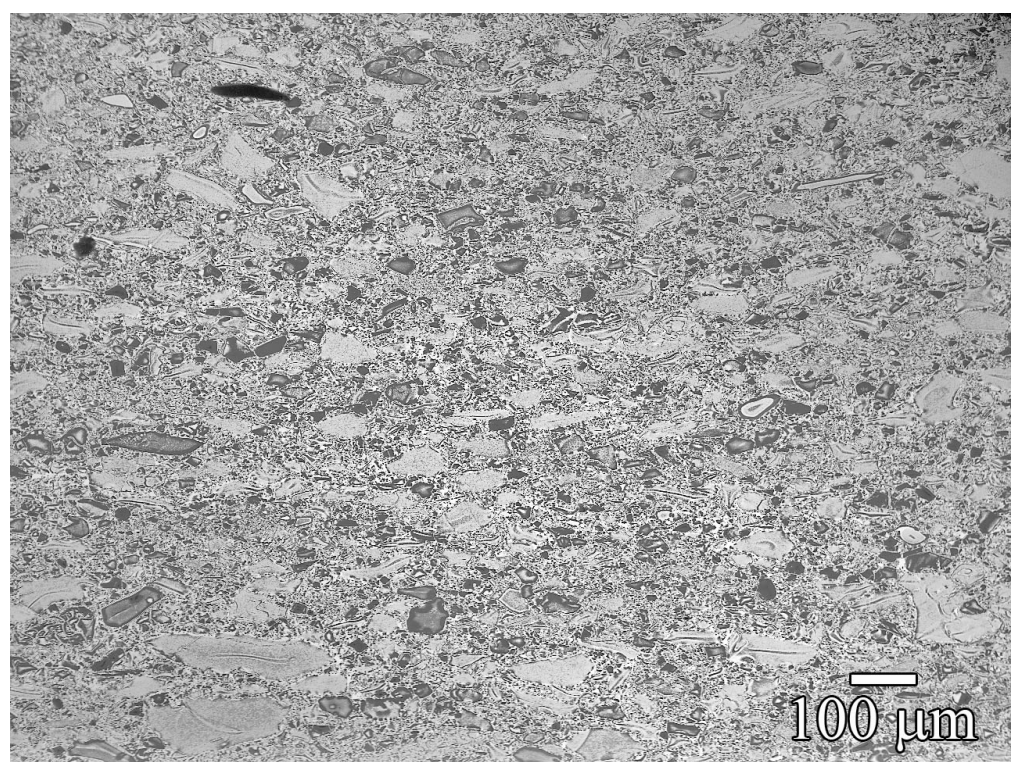

Figure 7. SEM backscattered electron image of HIP-processed iodine-loaded $\mathrm{Ag}^{0}$-aerogel (HIP-4). White and light gray inclusions are nanoparticles and micrometer-sized nodules of $\mathrm{AgI}$ and $\mathrm{Ag}_{2} \mathrm{~S}$ dispersed in a silica-based matrix. 


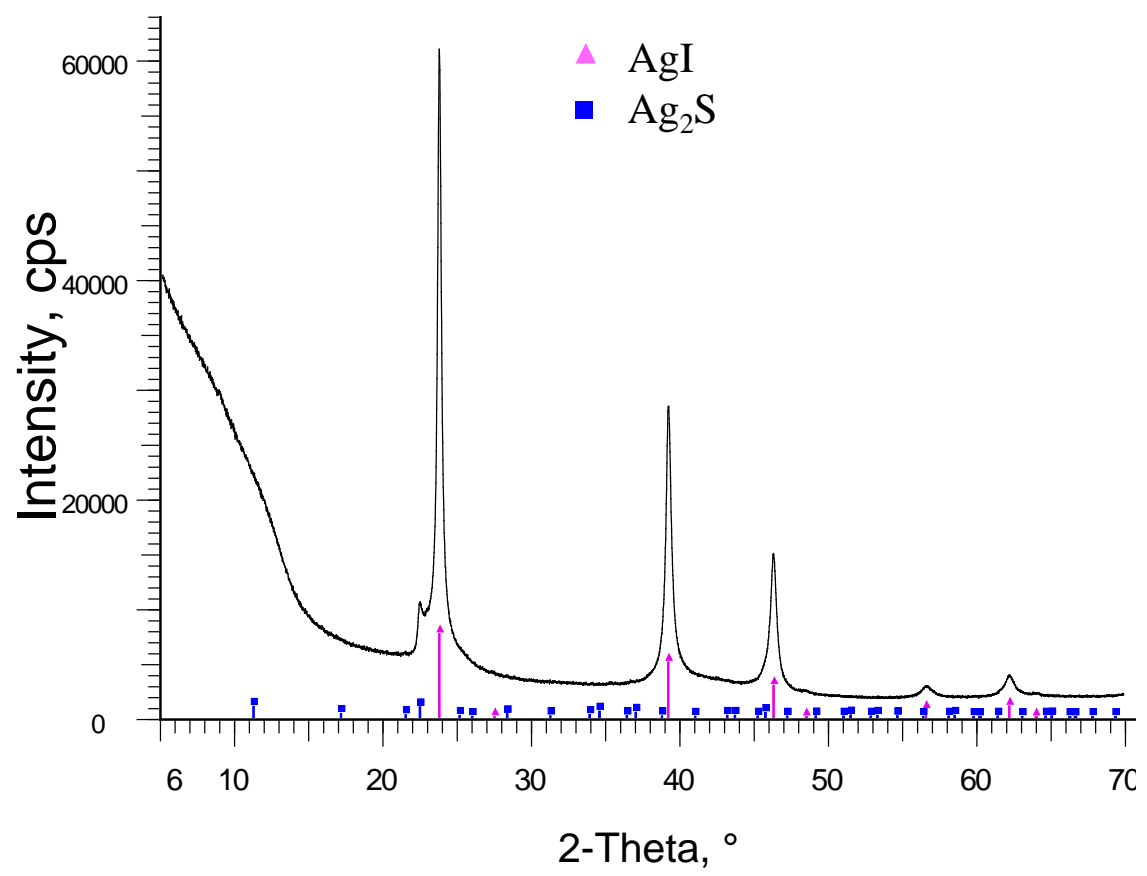

Figure 8. XRD pattern and identified phases for HIP-processed iodine-loaded $\mathrm{Ag}^{0}$-aerogel (HIP-4). 


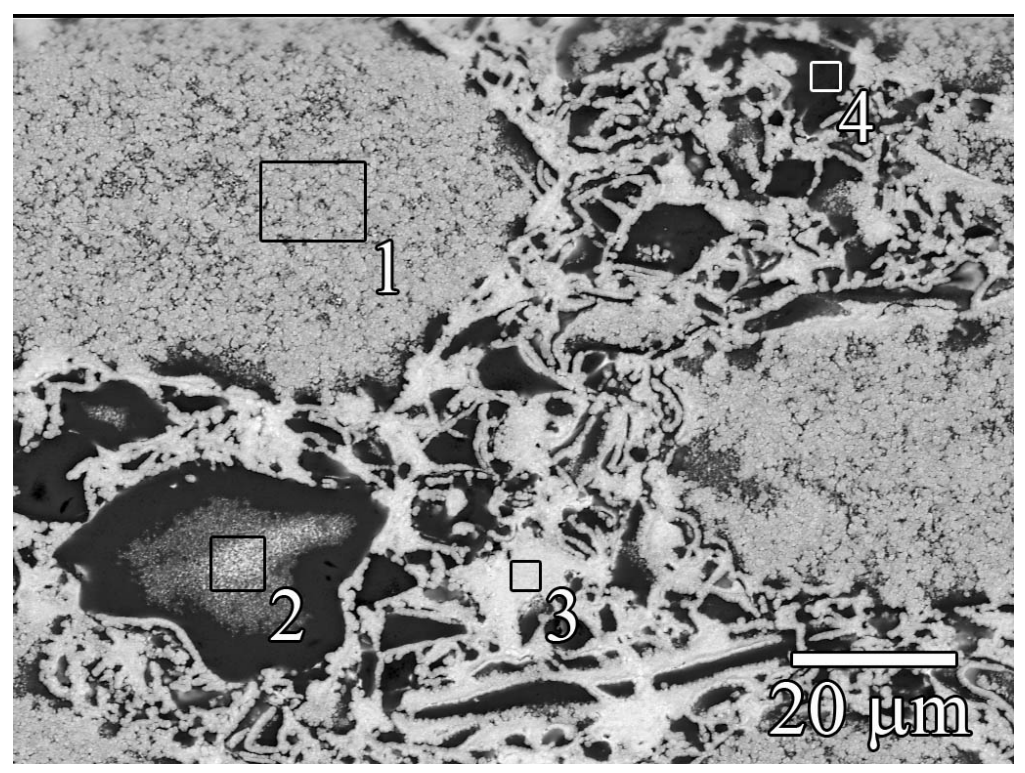

Figure 9. High magnification SEM backscattered electron image of HIP-processed iodine-loaded $\mathrm{Ag}^{0}$ aerogel (HIP-4). White and light gray inclusions are nanoparticles and micrometer-sized nodules of AgI and $\mathrm{Ag}_{2} \mathrm{~S}$ dispersed in a silica-based matrix. Elemental composition of highlighted areas 1-4 is summarized in Table 3. 